\title{
Erratum to: Pulmonary Hemodynamics Simulations Before Stage 2 SingleVentricle Surgery: Patient-Specific Parameter Identification and Clinical Data Assessment
}

\author{
Gregory Arbia, ${ }^{1}$ Chiara Corsini, ${ }^{2}$ Catriona Baker, ${ }^{3}$ Giancarlo Pennati, ${ }^{2}$ Tain-Yen Hsia, ${ }^{3}$ and Irene \\ E. Vignon-Clementel ${ }^{1}$ For the Modeling of Congenital Hearts Alliance (MOCHA) Investigators \\ ${ }^{1}$ INRIA Paris-Rocquencourt, Le Chesnay Cedex, France and UPMC Univ Paris 6, Laboratoire Jacques-Louis Lions, Paris, \\ France; ${ }^{2}$ Laboratory of Biological Structure Mechanics, Department of Chemistry, Materials and Chemical Engineering 'Giulio \\ Natta', Politecnico di Milano, Milan, Italy; and ${ }^{3}$ UCL Institute of Cardiovascular Science, and Great Ormond Street Hospital \\ for Children, NHS Foundation Trust, London, UK
}

Erratum to: Cardiovascular Engineering and Technology

Vol. 6, No. 3, September 2015,

PP. 268-280

DOI 10.1007/S13239-015-0212-3

Institutional author was not captured properly in the original publication of this article. The author list is correct as published here.

Address correspondence to Irene E. Vignon-Clementel, INRIA Paris-Rocquencourt, Le Chesnay Cedex, France and UPMC Univ Paris 6, Laboratoire Jacques-Louis Lions, Paris, France. Electronic mail: irene.vignon-clementel@inria.fr

The online version of the original article can be found under doi: 10.1007/s13239-015-0212-3. 